\title{
Secretin Attenuates the Hereditary Repetitive Hyperactive Movements in a Mouse Model
}

\author{
Katalin Köves • Gusztav Kiss • Andrea Heinzlmann • \\ Roberta Dochnal • M. Manczinger • Ágnes Pál • \\ I. Sípos • Gyula Szabó
}

Received: 2 February 2010 /Accepted: 11 June 2010 /Published online: 6 July 2010

(C) Springer Science+Business Media, LLC 2010

\begin{abstract}
It was previously demonstrated that secretin influenced the behavior of rats investigated by open-field test. In the present experiment, we have compared the effect of intracerebroventricular administration of $2 \mu \mathrm{g}$ of secretin on the behavior of CFLP white and Japanese waltzing mice. These latter animals exhibit stereotypic circular movements. The effect of secretin on the horizontal (ambulation) and vertical movements (rearing and jumping) was investigated in open-field test. The ambulation time and distance were shorter, and the number of rearing and jumping were much lower in Japanese waltzing mice than in CFLP white mice during 30 min-experimental period. In white mice, $2 \mu \mathrm{g}$ of secretin had no effect on the above-mentioned parameters; however, in Japanese waltzing mice, secretin enhanced the ambulation time and distance to the level of CFLP white mice, but did not influence the rearing and jumping. On the basis of the results, it was concluded that intracerebroventricularly administered secretin attenuated the stereotypic (circulating) movement and improved the horizontal movement indicated by the normalization of the ambulation time and distance; however, it did not influence the explorative behavior (rearing and jumping) in our special animal model.
\end{abstract}

G. Kiss · R. Dochnal · M. Manczinger · Á. Pál · I. Sípos •

G. Szabó

Department of Pathophysiology, Faculty of Medicine,

Albert Szent-Györgyi University,

Szeged, Hungary

K. Köves $(\square) \cdot$ A. Heinzlmann

Department of Human Morphology and Developmental Biology,

Semmelweis University,

Tủzoltó u. 58,

Budapest H-1094, Hungary

e-mail: koves@ana2.sote.hu
Keywords Open-field test · Japanese waltzing mouse · Stereotypic movement

\section{Introduction}

For a long time, secretin was known to be a gastrointestinal peptide. It was first demonstrated by Bayliss and Starling (1902) and characterized 60 years later by Jorpes et al. (1962). The presence of secretin in the nervous system was first demonstrated by Charlton et al. (1981). With the use of radioimmunoassay and high pressure liquid chromatography secretin was found in several regions of the central nervous system including the thalamus, hypothalamus, olfactory bulb, cerebral cortex, midbrain, septum, striatum, hippocampus, medulla, and the pons. The highest concentration was observed in two endocrine glands: the pineal body and the pituitary gland. The expression of the precursor gene was demonstrated in the medulla, pons, and the pituitary gland (Itoh et al. 1991). Secretin and its mRNA were also shown in the Purkinje cells of the cerebellar cortex (Yung et al. 2001; Köves et al. 2002, 2004).

Upcoming data demonstrate that secretin influences several functions in the nervous system. Intravenous (iv) infusion of secretin to rats induced c-fos gene expression in the central amygdala, area postrema, bed nucleus of stria terminalis (BNST), external lateral parabranchial and the hypothalamic supraoptic (SO) nucleus (Goulet et al. 2003). After intracerebroventricular (icv) administration of secretin many regions such as several brain stem, hypothalamic, and limbic structures (septum and amygdala) and the medial bank of the anterior prefrontal, orbitofrontal, and the piriform cortex showed activation of Fos protein in awake, freely moving rats (Welch et al. 2003). It is clear from the 
above-mentioned data that secretin influences c-fos expression in structures that are involved in behavior, stress adaptation and visceral responses. In the cells of pheochromocytoma cell line, secretin stimulates the activity of thyrosin hydroxylase, an enzyme important in catecholamine synthesis (Roskoski et al. 1989). Secretin also induces neurite outgrowth through cyclic-adenosine monophosphate (cAMP)-protein kinase pathway (Kim et al. 2006). In rats its icv administration decreased the open-field locomotor activity and novel object approach (Charlton et al. 1983). In the cerebellum secretin facilitates the glutamate and $\gamma$-amino butiric acid (GABA)-ergic inhibitory inputs onto Purkinje cells via a postsynaptic and cAMP-dependent mechanism as a retrograde messenger (Yung et al. 2001, 2006). It has also become evident that secretin is synthetized in the hypothalamic SO and paraventricular (PV) nuclei (Welch et al. 2004) and it regulates water homeostasis (Chu et al. 2009). In the $\mathrm{PV}$, there may be an interaction between secretin and corticotropin hormone-releasing hormone (CRH; Welch and Ruggiero 2005). More than a decade ago, it was found that secretin counteracts with the analgesic effect of morphine (Babarczy et al. 1995).

In the present study, we compared the effect of secretin on the behavior of two mouse-strains, CFLP white mouse and Japanese waltzing mouse (JWM). CFLP mice are usually used for testing the effect of various drugs on the behavior. JWM were also included because they exhibit a repetitive movement which is characteristic for several mental disorders. These animals run around in their cage nearly without stopping. The main aim of this experiment was to clarify whether icv administered secretin could influence the stereotypic behavior. Open-field test was used to investigate the effect of secretin on the behavior of the animals.

\section{Materials and Methods}

\section{Animals}

Adult (3-4 month old) CFLP white and JW female mice were used for the experiments. The animals were kept in a light- and temperature-controlled vivarium (lights on at 5:00 $\mathrm{h}$ and lights off at 19:00 $\mathrm{h}$; temperature $22 \pm 2^{\circ} \mathrm{C}$ ). Treating the animals was in accordance with the rules of the "European convention for the protection of vertebrate animals used for experimental and other scientific purposes", Strasbourg, 1986; permission \#: 37/1999.

\section{Implantation of Guiding Cannula}

Under general hexobarbital anesthesia $(0.08 \mathrm{mg} / \mathrm{gr} \mathrm{BW})$, a guiding cannula was implanted in the lateral ventricle of 12 CFLP white mice and $10 \mathrm{JWM}$. A day later, $2 \mu \mathrm{g}$ secretin in $2 \mu \mathrm{l}$ arteficial cerebrospinal fluid was administered through the cannula. Controls received only cerebrospinal fluid. We used female mice of both strains. The effect of secretin on behavior of the animals was examined using an open-field test. All animals were investigated in the morning.

\section{Behavior Study}

The open-field apparatus was a square open-field black cage with a side length of $60 \mathrm{~cm}$, surrounded by a $40 \mathrm{~cm}$ high wall. The floor of the cage was divided in $36(6 \times 6)$ small squares. A $60 \mathrm{~W}$ light was situated $1 \mathrm{~m}$ above the arena floor. Sessions started at 9 a.m. All animals were carried to the experimental room in their home cage. Each animal was placed in the center of the open field and was observed for $30 \mathrm{~min}$. Conducta 1.0 system (Experimetria Ltd., Budapest, Hungary) was used for monitoring the animals and analyzing the data.

The horizontal locomotor activity, defined as ambulation time and distance, and the vertical activity, rearing and jumping frequencies, defined as number of times the animals stood on their hind legs or jumped up, were evaluated.

Statistical analysis of the data was made by repeated measure analysis of variance (ANOVA). For significant ANOVA values, groups were compared by Tukey's test as post test. A probability value, $p<0.05$ was considered statistically significant.

\section{Results}

Detailed analysis of the horizontal and vertical movements revealed the following. In Fig. 1, white lines trace the movement of animals in the chamber. The horizontal movement of the control CFLP white mice and the JWM was basically different. The image demonstrates the characteristic feature of the movement of the two strains. The movement of white mice was mainly linear (Fig. 1a); however, the movement of JWM was circular in many cases (Fig. 1b). The white mice ran at the periphery of the arena, they tried to avoid the illuminated center (Fig. 1c). The motion of the JWM was opposite. They mainly remained in the center, did not bother about their environment (Fig. 1d). The stereotypy in JWM was indicated by lower ambulation time (Fig. 2a) and distance (Fig. 2b) than in the white mice.

Secretin considerably attenuated the stereotypic movement. The circular movement of the animals was strikingly reduced. It was also indicated by the difference in the ambulation time and the ambulation distance. In untreated JWM, it was nearly half of those than in white mice. 

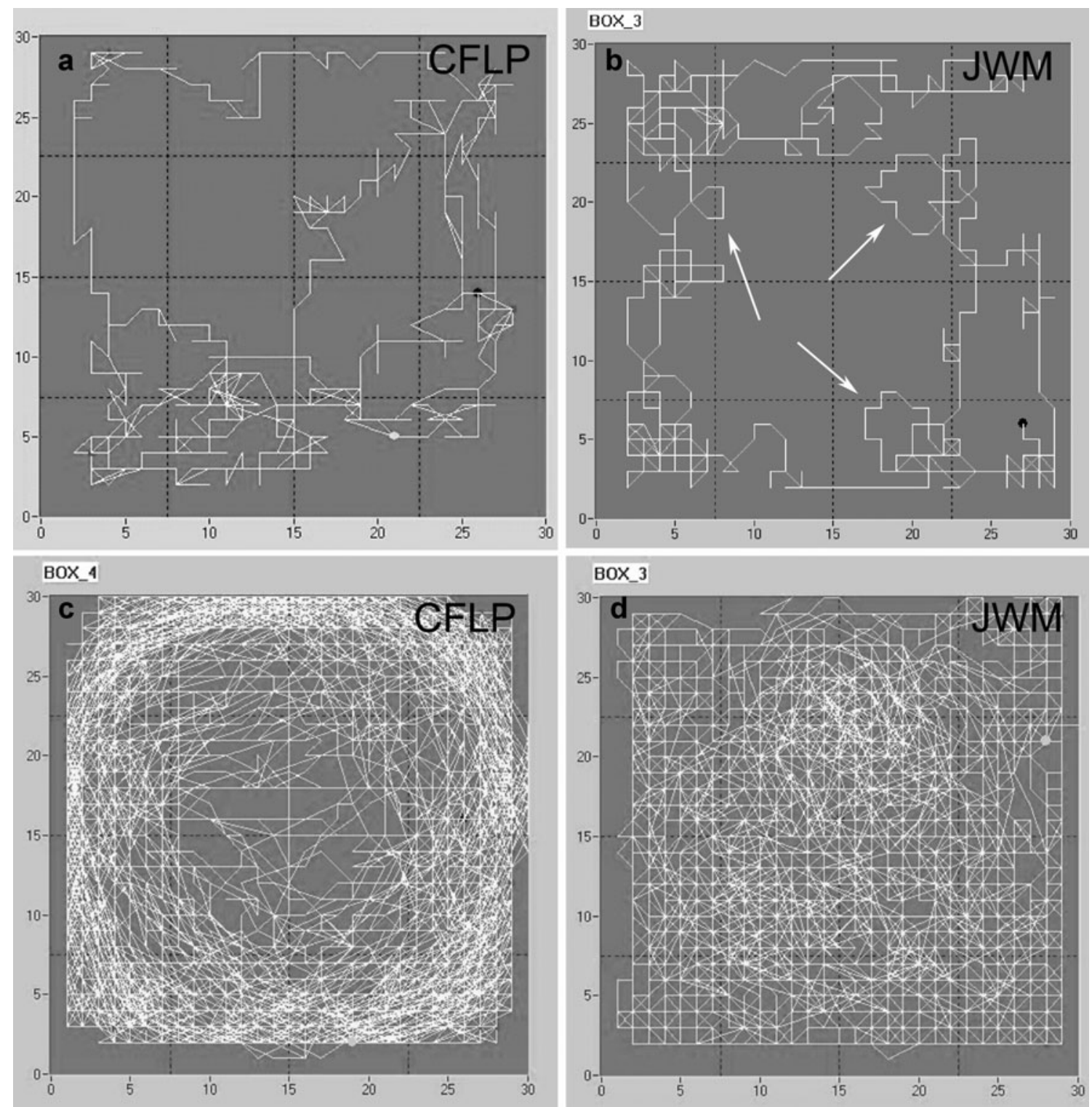

Figure 1 White lines in the panels demonstrate the horizontal movement of a CFLP white mouse and a JW mouse detected by the photosensors of the Conducta System. a The movement of CFLP white mouse is basically linear. b JW mouse besides the linear, exhibit circular movement indicated by loops. This phenomenon is pointed

Secretin did not influence these parameters in white mice; however, it enhanced the ambulation time and the distance in JWM to the level of CFLP white mice (Fig. 2a, b).

The analysis of vertical movements of the animals showed that the white mice tried to explore their environment. This behavior was indicated by rearing and jumping. They reared about 500 times during the 30-min examination period; however, JWM reared only nine times (Fig. 3a). The white mice jumped up more than 100 times, but the JWM only once during $30 \mathrm{~min}$ (Fig. 3b). Secretin did not influence these two parameters in either group (Fig. 3a, b). out by white arrows. In $\mathbf{a}$ and $\mathbf{b}$, the movement of animals was traced for $1 \mathrm{~min}$. $\mathbf{c}$ The white mouse tried to avoid the illuminated center of the arena, she remained at the periphery. d However, the JW mouse mainly resided in the center of the arena. The movement of the animals in $\mathbf{c}$ and $\mathbf{d}$ was detected for $5 \mathrm{~min}$

\section{Discussion}

The regulation of the behavior of animals is very complex process, many structures, neurotransmitters, and neuropeptides are involved in this mechanism. As it was mentioned in the "Introduction" section, one of these neuropeptides may be the secretin.

It was demonstrated nearly three decades ago that in rats, icv administration of secretin decreased the open-field locomotor activity and novel object approach (Charlton et al. 1983). To better understand the neuroactive role of secretin in the brain, Yamagata et al. (2008) recently 
a

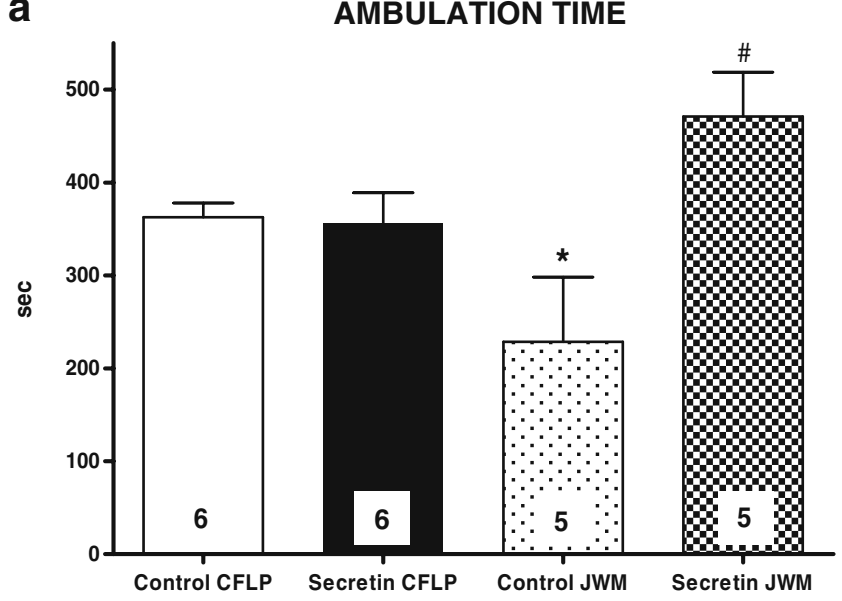

b

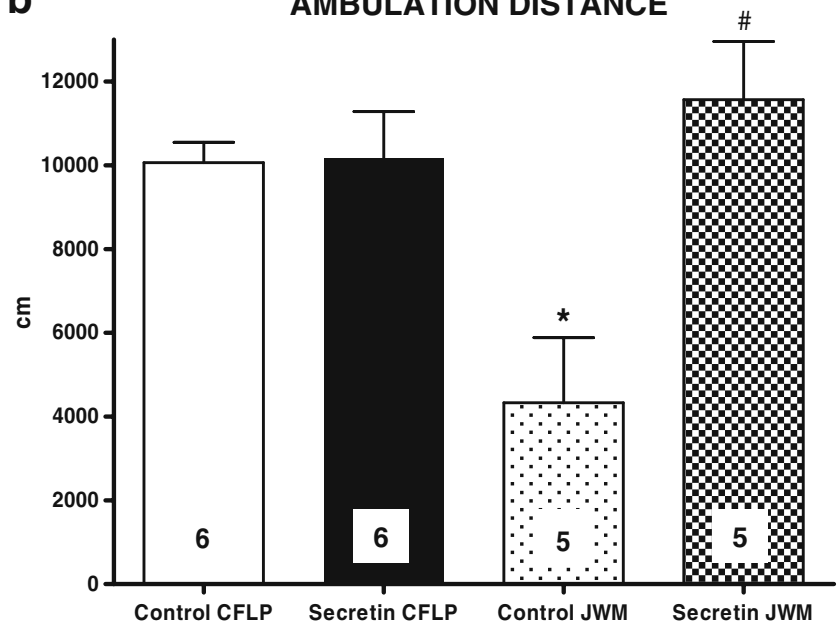

Figure 2 Diagram shows the quantitative analysis of the horizontal movement of the animals; a demonstrates the ambulation time and $\mathbf{b}$ the ambulation distance in both CFLP and JWM. In untreated JWM, the ambulation time and distance were nearly half of untreated white mice $(* p<0.01$ control CFLP vs. control JWM). Secretin did not influence these two parameters in CFLP white mice; however, in JWM, secretin significantly enhanced both ambulation time and distance ${ }^{\#} p<0.02$ control JWM vs. secretin JWM). These two parameters were even higher in secretin-treated JWM than in white mice; however, this difference was not statistically significant. Duration time of the observation was $30 \mathrm{~min}$

generated secretin-deficient mice. LacZ reporter was introduced in the secretin gene. In mutant mice, lacZ reporter was demonstrated in the molecular layer of the hippocampus, dentate gyrus, posterior commissure, habenula, cerebellum, olfactory glomeruli, and the dorsal tegmentum. No obvious morphological and developmental abnormalities were found in the brain of these animals. Physiological examination was only carried out in the hippocampus using electrophysiological approach. A reduction in the long termpotentiation (LTP) induction and LTP maintenance was found.
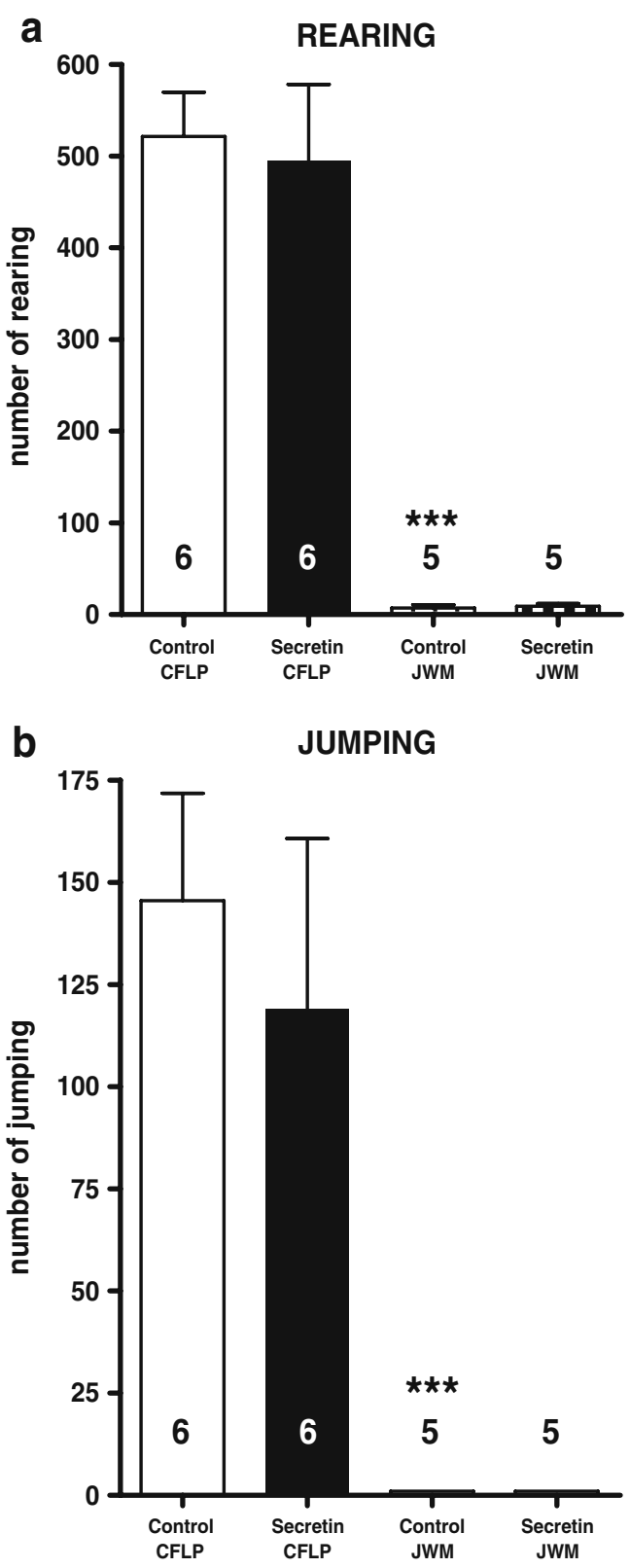

Figure 3 Diagram shows the quantitative analysis of the vertical movement of the animals (rearing and the jumping). a The white mice reared more than 500 times during the 30 min-observation time but the JWM reared only seven to nine times. $\mathbf{b}$ The white mice jumped up about 150 times but the JWM only once during the observation period. This difference was highly significant $(* * * p<0.0001$ control CFLP vs. control JWM). Secretin did not influence these parameters in either strain

These results suggest that both secretin and its receptor are necessary for normal hippocampal function. The effect of secretin is probably mediated through the glutamate, an excitatory amino acid critical for LTP. This hypothesis is supported by the findings of Kuntz et al. (2004) who demonstrated that secretin increased GABA levels in the rat hippocampus using microdialysis technique. 
The effect of secretin may be also mediated via other structures of the nervous system. Two important candidates may be the amygdala and the BNST. It was demonstrated previously that iv or icv administration of secretin to male rats induced c-fos gene expression in structures belonging to the limbic system including amygdala and BNST (Goulet et al. 2003; Welch et al. 2003). The role of these two structures in the behavior of animals is strongly suggested. It was recently demonstrated by Carty et al. (2010) that hypoxia induced by carotid ligation in neonatal rats (on postnatal day 3 ) decreased the number of CRH neurons in the central amygdala. In these animals, the decreased number of $\mathrm{CRH}$ neurons was inversely correlated with the locomotor activity and explorative behavior in open-field test.

A lot of evidence suggests that activity of BNST mediates fear, stress, and anxiety-like behavior in human and animals as well. The excitotoxic lesion of BNST blocked the anxiety behavior induced central administration of $\mathrm{CRH}$; however, the lesion of the central amygdala did not influence the effect of CRH (Walker et al. 2009; Hammack et al. 2009). With the use of tracing technique, direct connection between the two structures was demonstrated (Davis and Whalen 2001).

The role of the nigro-striatal mesolimbic dopaminergic system in the hyperactive locomotor activity and stereotipic movement is also suggested (Pycock and Marsden 1978). Amphetamine, apomorphine, and LSD 25 can induce hyperactive stereotypic movements acting on dopamine and serotonin receptors (Jaton et al. 1981).

It is well known that the cerebellum coordinates the motor activity of the organism. Both secretin and its receptors were demonstrated by Yung et al. $(2001,2006)$. They also demonstrated that secretin facilitated the GABA-ergic inhibitory inputs onto Purkinje cells via a postsynaptic and cAMP-dependent mechanism as a retrograde messenger. The participation of the cerebellum in the stereotypic movements was also suggested by Pierce and Courchesne (2001). They observed with the use of magnetic resonance imaging that the size of the VI. and VII. lobes of the cerebellar vermis is negatively correlated with the seriousness of the repetitive movements in autistic patients.

In this present work, we investigated the effect of secretin on the locomotor activity and on the explorative behavior in JWM and CFLP white mice. Our animal model, JWM showed a repetitive circular movement, a stereotypic behavior which also occurs in several mental disorders. Secretin strikingly improved the stereotypy. The animals exhibited more linear movement instead of circular one. In the computerized analysis, it was indicated by the enhancement of the ambulation time and distance during the observation period. The secretin did not influence the explorative behavior which was indicated by rearing and jumping of animals. In our experimental conditions, none of the parameters was influenced by secretin in the control CFLP white mice.

The question arises how secretin can influence the locomotor activity of JWM. Most likely, it acts through structures where secretin receptors were demonstrated and which are related to hyperactive movements. It is most likely that the amygdala-BNST CRH-containing neuronal circuits are responsible for this effect. The role of the nigrostriatal system and the cerebellum is not excluded.

In summary, the data show that secretin influences the locomotor activity of a special animal model. Its effect on the repetitive movement is beneficial. It normalizes the horizontal movement (ambulation time and distance), although it does not improve the explorative behavior of the animals.

Acknowledgment This work was partially supported by the Department of Human Morphology and Developmental Biology, Semmelweis University and ETT-Grant (355-08) to Gyula Szabó. We say thanks to Anna Takács for her technical assistance.

\section{References}

Babarczy E, Szabó G, Telegdy G (1995) Effects of secretin on acute and chronic effects of morphine. Pharmacol Biochem Behav 51:469-472

Bayliss WM, Starling EH (1902) The mechanism of pancreatic secretion. J Physiol 28:325-353

Carty ML, Wixey JA, Kesby J, Reinebrant HE, Colditz PB, Gobe G, Buller KM (2010) Long-term losses of amygdala corticotropin-releasing factor neurons are associated with behavioural outcomes following neonatal hypoxia-ischemia. Behav Brain Res 208:609-18

Charlton CG, O'Donohue TL, Miller RL, Jakobowitz DM (1981) Secretin immunoreactivity in rat and pig brain. Peptides 2:45-49

Charlton CG, Miller RL, Crawley JN, Handelmann GE, O'Donohue TL (1983) Secretin modulation of behavioral and physiological functions in the rat. Peptides 4:739-742

Chu JY, Lee LT, Lai CH, Vaudry H, Chan YS, Yung WH, Chow BK (2009) Secretin as a neurohypophysial factor regulating body water homeostasis. Proc Natl Acad Sci USA 106:15961-6

Davis M, Whalen P (2001) The amygdala: vigilance and emotion. Mol Psychiatry 6:13-34

Goulet M, Shiromani PJ, Ware CM, Strong RA, Boismenu R, Rusche A (2003) Secretin i.v. infusion activates gene expression in the central amygdala of rats. Neuroscience 118:881-8

Hammack SE, Guo J-D, Hazra R, Dabrowska J, Myers KM, Rainnie DG (2009) The response of neurons in the bed nucleus of the stria terminalis to serotonin: implications for anxiety. Prog Neuro-Psycho Biol Psych 33:1309-20

Itoh N, Furuya T, Ozaki K, Ohta M, Kawasaki T (1991) The secretin precursor gene. Structure of the coding region and expression in the brain. J Biol Chem 266:12595-8 
Jaton AL, Vigouret JM, Dravid A (1981) Involvement of serotoninergic mechanisms in the circling behaviour induced by apomorphine and LSD 25 in rats. J Physiol Paris 77:405-11

Jorpes JE, Mutt V, Magnusson S, Steele BB (1962) Amino acid composition and en-terminal amino acid sequence of porcine secretin. BBRC 9:275-9

Kim HS, Yumkham S, Kim SH, Yea K, Shin YC, Ryu SH, Suh PG (2006) Secretin induced neurite outgrowth of PC12 through cAMP-mitogen-activated protein kinase pathway. Exp Mol Med 38:85-93

Köves K, Kausz M, Reser D, Horváth K (2002) What may be the anatomical basis that secretin can improve the mental functions in autism? Regul Pept 109:167-172

Köves K, Kausz M, Reser D et al (2004) Secretin and autism: a basic morphological study about the distribution of secretin in the nervous system. Regul Pept 123:209-216

Kuntz A, Clement HW, Lehnert W, Van Calker D, Hennighausen K, Gerlach M, Schulz E (2004) Effects of secretin on extracellular amino acid concentrations in rat hippocampus. J Neural Trans 111:931-939

Pierce K, Courchesne E (2001) Evidence for a cerebellar role in reduced exploration and sterotyped behavior in autism. Biol Psychiatry 49:655-664

Pycock CJ, Marsden CD (1978) The rotating rodent: a two component system? Eur J Pharmacol 47:167-75

Roskoski R Jr, White L, Knowlton R, Roskoski LM (1989) Regulation of thyrosine hydroxylase activity in rat PC12 cells by neuropeptides of the secretin family. Mol Pharmacol 36:92531

Walker DL, Miles LA, Davis M (2009) Selective participation of the bed nucleus of stria terminalis and CRF in sustained anxiety-like versus phasic fear-like responses. Prog Neuro-Psychopharmacol Biol Psychiatry 33:1291-1308

Welch MG, Ruggiero DA (2005) Predicted role of secretin and oxytocin in the treatment of behavioral and developmental disorders: implication for autism. Int Rev Neurobiol 71:273315

Welch MG, Keune JD, Welch-Horan TB, Anwar N, Anwar M, Ruggiero DA (2003) Secretin activates visceral brain regions in the rat including areas abnormal in autism. Cell Mol Neurobiol 23:817-37

Welch MG, Keune JD, Welch-Horan TB, Anwar N, Anwar M, Ludwig RJ, Ruggiero DA (2004) Secretin: hypothalamic distribution and hypothesized neuroregulatory role in autism. Cell Mol Neurobiol 24:219-241

Yamagata T, Urano H, Weeber EJ, Nelson DL, Nishijima I (2008) Impaired hippocampal synaptic function in secretin-deficient mice. Neuroscience 154:1417-1422

Yung WH, Leung PS, Ng SSM, Zhang J, Chan SCY, Chow BKC (2001) Secretin facilitates GABA transmission in the cerebellum. J Neurosci 21:7063-7068

Yung WH, Chan YS, Chow BK, Wang JJ (2006) The role of secretin in the cerebellum. Cerebellum 5:43-8 